\title{
Vertigonun medikal tedavisi
}

\section{Medical treatment of vertigo}

\section{Serkan TURSUN' ${ }^{1}$, Gökçe ŞiMŞEK²a, Nuray BAYAR MULUK²}

${ }^{1}$ Kırıkkale Üniversitesi Tıp Fakültesi, Çocuk Hastalıkları Anabilim Dalı, Kırıkkale

${ }^{2}$ Kırıkkale Üniversitesi Tıp Fakültesi, Kulak Burun Boğaz Anabilim Dalı, Kırıkkale, TÜRKiYE

\section{öz}

Vertigo (baş dönmesi), sadece kulak burun boğaz değil, aile hekimliği pratiğinde de sık rastlanan bir hastalık grubunu oluşturmaktadır. Etyolojisinde çok çeşitli hastalıkların bulunduğu bu patolojinin kesin tanısı her zaman mümkün olamamaktadır. Tedavide öncelikli amaç, akut vertigo atağı ile gelen hastanın semptomlarının azaltılması olmalıdır.Vertigonun medikal tedavisinin anlatılacağı bu bölümde ülkemizdeki mevcut ilaçlar ve tedavi dozlarından da bahsedilecektir.

Anahtar kelimeler:Vertigo, medikal tedavi

\section{ABSTRACT}

UVertigo (dizziness), constitutes a common group of diseases not only in the practice of otolaryngology, also in the practice of family physicians. There are various diseases in the etiology of this pathology and definitive diagnosis is not always possible. The primary objective in the treatment should be reduction of symptoms in the patients with acute attacks of vertigo. In this section, medical treatment of vertigo will be described with mentioning of the current medications and their therapeutic doses available dosage in our country.

Keywords: : Vertigo, medical therapy

Corresponding Authora: Dr. Gökçe ŞiMŞEK. Kırıkkale Üniversitesi Tıp Fakültesi Hastanesi, KBB Anabilim Dalı, 71450 Yahşihan, Kırkkale, TURKEY Phone: 00905062417502

e-mail: drgokcesimsek@hotmail.com

Received 18.01.2016 accepted 18.02.2016

Doi: 10.18663/tjcl.298255 


\section{Giriş}

Vertigo (baş dönmesi), kısaca hareket illüzyonu veya halüsinasyonu olarak tarif edilir. Vertigonun etyolojisinde periferik veya santral vestibüler patolojiler, vizüel bozukluklar, serebellar, piramidal, kardiyak veya metabolik hastalıklar rol oynayabilir [1]. Bu nedenle vertigolu hastalarin çok dikkatle incelenmesi gerekmektedir.

Anamnez vertigolu hastalarda çok önemlidir. Vertigonun özellikleri, birlikte bulunan diğer semptomlar, özgeçmiş araştırılmalıdır. Daha sonraki aşamada kulak burun boğaz muayenesini de içeren fizik muayene yapılmalıdır. Hastada aktif bir kulak enfeksiyonu varsa ya da nöroşirujik ameliyat, kaza ya da aminoglikozid kullanımına bağlı otolojik travma öyküsü mevcutsa vertigonun nedeni anlaşılabilir [1]. Tümör ya da infarkt gibi santral bir patoloji varsa, beraberinde görülen nörolojik bulgular ve radyolojik yöntemlerle tanı konulması mümkün olur. Kronik orta kulak iltihabına bağlı uzun süredir akan kulaklarda ani başlangıçlı vertigo, perilenfatik fistül gibi ciddi bir komplikasyonun geliştiğini düşündürür ve bu durum acil girişim gerektirdiğinden ilgili uzmanlık alanına sevki önerilir. Vertigo otitis media, serebellum tümörü gibi bilinen bir etiyolojik faktöre bağlı ise tanı konulan hastalığın tedavisi yapılır [1]. Ancak genellikle vertigoya neden olan hastalıklar kolay ve kesin olarak teşhis edilemez. Vertigonun kesin tanı koyulabilen bir hastalığa bağlı olmadığı ve spesifik tedavi imkanının mümkün olmadığı bu gibi durumlarda ampirik tedavi uygulanır.

Vertigo nedeniyle hekime başvuran hastalarda en önemli aşamalardan biri de var olan rahatsızlığın baş dönmesi mi yoksa dengesizlik mi olduğunu anlamaktır [2]. Eğer sorun dengesizlik ise medikal tedavide yeni bir ilaç vermektense uygun tanı ve tedaviyi belirlemek için alınan tüm ilaçları kesmek ve hastayı ilaçsız bir süre gözlemek daha doğru bir yaklaşım olacaktır. Yine, vertigo ve dengesizlik yakınmaları en çok ileri yaşı hastalarda görülür. Bu yaş populasyonunda dengesizlik periferik kaynaklı olmaktan çok yaşlanma ile oluşan santral nedenlerle gelişir. Ayrıca bu hastalar çok çeşitli ve farklı ilaç kullanmaktadırlar. Bu ilaçlar dengesizliği ortadan kaldırıcı değil, ortaya çıkaran özellikler gösterir. Çoklu ilaç kullanan hastalarda kullanılan ilaç sayısı ile artan ve kontrolü güçleşen yan etki ve komplikasyonların başında vertigo ve benzeri şikayetler yer almaktadır. Bu durum da zaten yaşa bağlı denge sistemi disfonksiyonu olan hastalarda klinik tabloyu ağırlaştırmaktadır. Bu sebeple özellikle yaşlılara yeni ilaç reçete etmek yerine alınan ilaç sayısını azaltmak daha isabetli bir yaklaşım olacaktır.

Vertigo beraberinde eşlik eden belirtiler sıklıkla bulantı ve kusmadır. Tedavide kullanılan ilaçlar şunlardır [3]:

1-Vestibüler supresanlar,

2- Antiemetik ilaçlar,

3- Diğer ilaçlar
Vestibüler supresanlar antihistaminikler, antikolinerjikler ve benzodiazepinler olmak üzere 3 gruptur. Vestibüler supresanlar vestibüler uyarılırlığı azaltmak yanında bulantı ve kusmada etkilidirler. Antiemetikler ise daha seçici olup bulantı ve kusmayı engellerler. Bunlar dışında üzerinde hala çalışmalar yapılan ve gelecek vadeden değişik ilaçlar mevcuttur. Aşağıda vertigo tedavisinde kullanılan ilaçlar etki mekanizması, yan etkiler, doz, pozoloji ve ülkemizde kullanılan jenerik isimleri ile ele alınacaktır.

\section{Vestibüler Supresanlar}

1.1.Antihistaminikler: Histaminin santral vestibüler iletideki rolüçokaçıkolmamakla beraber harekethastalığıve başdönmesi şiddetini semptomların başlamasından sonra bile başarı ile azalttığı saptanmıştır [4]. Vertigo tedavisinde kullanılan tüm antihistaminiklerin aynı zamanda antikolinerjik yan etkileri (ağız kuruluğu, pupil dilatasyonu, sedasyon gibi) de bulunmaktadır. Astemizol dışındaki tüm antihistaminikler kan beyin bariyerini geçerek baş dönmesini hafifletirler. Antihistaminiklerin etkisinin başlaması için geçen süre 20-30 dakikadır. Tepe plazma düzeyleri 1-2 saatte oluşur ve yarı ömürleri yaklaşık 8 saattir. Bu nedenle sıklıkla 2x1 pozolojide kullanılırlar [5].

1.1.1.Dimenhidrinat (Dramamine ${ }^{\circledR}$, Anti-em ${ }^{\circledR}$ ): Akut atak sırasında ilk tercih edilecek ilaç bir antihistaminik olan dimenhidrinattır. Bulantı ve kusmalar üstüne de oldukça etkilidir. Hafif derecede karıncalanma ve uyku hali meydana getirir. Ülkemizde 50 mg'lık ampul ve tablet formları bulunmaktadır. Tablet olan formlar: Anti-em 12 tablet $^{\circledR}$, Anti-em $20 \mathrm{tb}^{\circledR}$, Dramamine 12 tablettir $^{\circledast}$. Ampul formu ise Dramamine ampul ${ }^{\circledR}$ olarak mevcuttur. Akut atak sırasında hızlı rehabilitasyon ihtiyacından parenteral kullanım tercih edilir. Dramamine ampul ${ }^{\circledR}$, parenteral uygulanır. İdame tedavide ağız yolu ile 50 mg'lık tabletlerinden üç ve ya dört tane alınır [5]. Ancak vestibüler kompanzasyona fırsat vermek için 1 haftadan fazla kullanımı önerilmez. Profilakside aylarca kullanım kompanzasyonu baskıladığından tavsiye edilmez. Vertigo atağı sonrası uzun süre dimenhidrinat kullanan ve hala şikayetleri olan hastaların ilk olarak ilacı kesilmelidir.

1.1.2.Difenhidramin (Benison $^{\circledR}$, Allenik $^{\circledR}$, Metorfan ${ }^{\circledR}$ ): Antihistaminik grubunda yer alan bir ilaçtır ancak vertigonun spesifik ilacı değildir. Ancak profilakside, taşıt tutmasında, bulan $\neg$ tı ve kusmalarda kullanılmaktadır. Etkisi 4-6 saat sürer ve tedavi dozlarında uyuklama çok sık görülür. Günlük doz başlangıçta 50 mg'dır [5].

1.1.3.Meklizin (Antivert ${ }^{\oplus}$ ): Vestibüler kaynaklı baş dönmeleri ile birlikte olan bulantı ve kusmalara karşı etkili bir antihistaminik ajandır. Yavaş etki yapar fakat etkisi uzundur ve 24 saat sürer. Uyuklama, görmede buحlanıklık, ağız kuruluğu ve yorgunluk önemli yan etkileridir. Günlük doz hastalığın şiddetine göre 25-100 mg arasında değişir [5].

1.1.4.Prometazin: Diğer aynı grup fenotiazinlere göre çok kuvvetli antihistaminik etki gösterir ve ayrıca kuvvetli santral 
kolinerjik etkiye sahiptir. Bu yüzden taşıt tutmalarında ve baş dönmele $\neg$ rinde tercih edilen bir ilaçtır. Bulantı ve kusmalarda başlangıç dozu 25 mg'dır ve her 6 saatte bu dozun yarısı klinik tabloya göre verilebilir. Rektal yolla da etkilidir. Tedavi dozlarında yan et $\neg$ kileri çok azdır [4]. Ülkemizde tek başına bulunmamaktadır.

1.2.Antikolinerjikler (Skopolamin ${ }^{\circledR}$, Buscopan ${ }^{\circledR}$, Butopan ${ }^{\circledR}$, Spazmol ${ }^{\circledR}$ ): Antikolinerjikler muskarinik reseptörleri etkiler ve harekete bağlı hassasiyet ve dengesizliği azaltırlar [6]. Vestibüler kompanzasyon sağlandıktan sonra uygulandıklarında geriye döndürülebilir bir aşırı kompanzasyon haline neden olabilir [5]. Bu durumdaki hastalar dengelerini koruyabilmek için görsel ve proprioseptif uyarılara normalden fazla bağımlıdırlar. Vertigo tedavisinde santral etkili antikolinerjikler kullanılır. Kan beyin bariyerini geçemeyen ilaçların vertigo tedavisinde yeri yoktur. Hepsinin ortak yan etkileri ağızda kuruluk, görme bozuklukları ve sedasyondur. Prostat hipertrofisi veya glokomu olan hastalarda kullanılmaz. Bu amaçla kullanılan Skopolamin ${ }^{\circledR}$ ve Buscopan ${ }^{\circledR}$ mevcuttur. Özellikle Transdermal Skopolamin ${ }^{\circledR}$ yavaş da olsa da etkilidir [7]. Yetişkin dozu: 0,5 mg PO/IM/SC [5].

Zaman içinde muskarinik reseptörlere spesifik ajanların geliştirilmesi ile yan etkisi minimal, etki profili maksimal antivertiginöz ajanların kullanımı gündeme gelebilir.

1.3.Benzodiazepinler: Bu ilaçlar vestibülodepresan etki gösterir. Gama amino butirik asit (GABA) sistemin etkisini arttırdığı sanılmaktadır. Bu şekilde beyin sapının vestibüler çekirdekler üstüne yaptığı inhibisyon etkisi kuvvetlenir [8]. Bu ilaçlar düşük dozlarda baş dönmesi kontrolünde çok etkili olmasına rağmen bağımlılık yapıcı etkileri nedeniyle hasta tarafından suistimal edilebilir. Bunun yanında hafıza kayıpları, düşme ve yaralanma riski, vestibüler kompanzasyonda gecikme diğer yan etkilerdir. Lorazepam, klonazepam ve diazepam düşük dozlarda kullanılabilir ancak çok kuvvetli bir çekilme sendromuna neden olduğu için bu gruptan alprazolam vertigo tedavisinde tercih edilmez.

1.3.1.Diazepam $\left(\right.$ Diazem $^{\circledR}{ }$, Diapam $^{\circledR}$, Lizan $^{\circledR}$, Nervium $^{\circledR}$ ): Genel sedatif etkisi vertigoya bağlı oluşan anksiyete ve stres oluşumuna engel olarak vertigoyu arttıran kısır döngüyü kırar. Bunun yanında antivertiginöz etkisi de olması bu ajanı özellikle akut vertigo atağında yararlı hale getirmektedir [9]. Vertigo nöbetlerinde erişkinlerde başlangıç dozu olarak 5 mg'la başlanır. Hastada bulantı ve kusma varsa bu miktar parenteral olarak da verilir. Her üç saatte bir 5 mg'lık doz ağız yolu ile tekrarlanır. Bu şekilde tüm güne yayılan bir sedasyon elde edilir. Parenteral kullanım sırasında solunum sistemini deprese edici etki gösterir. Bu yüzden $\mathrm{KOAH}$ (kronik obstrüktif akciğer hastalıkları)'ı hastalarda kullanılması kontraendikedir. Ayrıca uyku apnesi olan hastalarda da apne süresi ve sıklığını arttırabilceğinden önerilmez. Hipotansif etkisi nedeniyle ilaç uygulaması öncesi tansiyon kontrölü yapılması önerilir.
Yukarıda bahsedilen tüm vestibüler supresanlar vestibüler kompanzasyon sürecini geciktirir. Akut vertigo atağından sonraki ilk günlerde hastanın şikayetleri çok yoğundur ve bu dönemde vestibüler supresanların kullanımı gereklidir. Ancak ilaçlar en kısa sürede (ortalama 1 hafta) azaltılarak kesilmeli ve kompanzasyon gelişimine fırsat tanınmalıdır. Hastanın atak sonrası baş dönmesi şikayeti yoksa uzun süre antivertiginöz tedavi almasına da gerek yoktur.

\section{Antiemetikler}

Bulantı ve kusmanın baskılanmasında kullanılan ajanlardır [8]. Beyinde emezise neden olan ana bölgeler area postremada lokalize kemoreseptör trigger zon ve beyin sapındaki retiküler formasyondur. Antiemetiklerin büyük çoğunluğu bu bölgeler üzerinden etki eder. Vestibüler supresan grubundaki ajanların hepsi aynı zamanda antiemetik özelliklere de sahiptir. Bu grupta antidopaminerjik ilaçlar yer almaktadırlar. Droperidol, metoklopramid, ondansetron, proklorperazin, trimetobenzamid antidopaminerjik ajanların başında gelir [10].

2.1.Droperidol (Dehidrobenzperidol): Bulantı ve kusmayı önlemekiç̧in ağızyolu ile 2,5-10 mg dozunda kullanılır. Parenteral olarak 5 mg dozunda kullanılır. Ancak hipotansiyon, sedasyon gibi ekstrapiramidal yan etkilerine dikkat etmek gerekir [5].

2.2.Proklorperazin: Antiemetik, analjezik ve sedatif etkileri vardır. Dozu ağız yoluyla ya da parenteral olarak her 6 saatte 10 mg'dır. Antiemetik etkisi kuvvetlidir. Hipotansiyon ve karıncalanma gibi yan etkiler sık görülür. Tedavi dozlarında bile ekstrapiramidal belirtiler ortaya çıkabilir. Bunlar Parkinson benzeri titremeler, yüzde ve ensede spazmodik kontraksiyonlar, karpopedal spazm ve motor zayıflık olabilir. EKG 'de QRS uzaması ve ventriküler aritmi gibi bazı bozukluklar ortaya çıkarabilir [5].

Vestibüler supresan ve antiemetiklerin temel kullanım endikasyonlarını özetlemek gerekirse:

- $\quad$ Akut periferik vestibulopati: bulantı için ilk 1 hafta.

- Akut beyin sapı ya da serebellar lezyonlar: eşlik eden baş dönmesi ve bulantı için

- Sık tekrarlayan vertigo atakları

- Taşıt tutması

\section{Vertigo tedavisinde kullanılan diğer ilaçlar}

3.1.Betahistin (Betaserc ${ }^{\circledast}$, Vasoserc ${ }^{\circledR}$, Vestibo ${ }^{\circledR}$, Rotastin ${ }^{\circledR}$ ): Vertigo tedavisinde sıklıkla kullanılan santral etkili bir histamin analoğudur. Merkezi sinir sisteminde postsinaptik H1 agonisti, presinaptik H3 antagonistidir. Hem histamin analoğunun hem de antagonistinin denge sistemi üzerinde etkili olması tam olarak aydınlatılamamıştır ancak son etkinin histaminerjik uyarının artması olduğu düşünülmektedir [11]. İç kulakta vazodilatasyon yaparak mikro dolaşımı arttırır ayrıca beyin sapında vestibüler çekirdekler üzerinde düzenleyici etkisi mevcuttur. Uzun süre kullanımında dahi yan etki profili açısından oldukça güvenlidir. Bu özelliği nedeni ile Meniere 
hastalığında uzun zamandır yaygın olarak kullanılmaktadır. Yakın zamanda yapılan bir meta-analizde Meniere hastalığında ve vestibüler vertigo tedavisinde betahistinin, plaseboya iki kat üstün etkinlikte olduğu saptanmıştır [12]. Ayrıca kulak cerrahisi sonrası betahistinin postoperatif bulantı, kusma ve baş dönmesi şikayetlerini azalttığı bildirilmiştir [13].

Feokromasitomada kullanımı sakıncalıdır. Astım ve peptik ülserde dikkatli kullanılmalıdır. Etkisi az sayıda da olsa kaliteli bilimsel çalışmalarla gösterilmiş nadir ilaçlardandır. Sıklıkla hatalı olarak düşük dozlarda kullanılır ve bu dozlarda etkisi görülmeyebilir. Başlangıç dozu günde en az 2 sefere bölünecek şekilde 48 mg olmalıdır. Ülkemizde 8, 16 ve 24 mg'lık formları mevcuttur [5].

3.2.Pirasetam (Nootropil $^{\circledR}$ ): Demans ya da bilişsel bozukluğu olan hastalarda klinik iyileşme sağlayan nootropik ajanlardan biridir. Vasküler etkisi ile yaygın olarak serebral mikrosirkülasyonu arttırmak amacı ile kullanılan pirasetamın beyinde nörotransmisyonu ve hücresel enerji miktarını düzenleyerek santral sistemdeki dengesizlikleri giderici etkisi vardır. Özellikle membran iletiminde kolinerjik ve eksitatör amin (NMDA) reseptörlerinin sayısını ve fonksiyonunu düzenler. Kafa travması, vertebrobasiler yetmezlik gibi santral nedenlerde ve periferik hastalıklarda vertigonun şiddetini azalttığı, tekrarlayıcı hastalıklarda hem vertigo şiddetini azalttığı hem de atak sıklığını düşürdüğü bildirilmiştir [14]. Pirasetam ayrıca trombosit agregasyonunu azaltarak, antitrombotik etki göstermektedir. Yaşlı hastalarda özellikle etkiliolduğu rapor edilmiştir. Gebelikte ve ağır renal yetmezlikte kullanılmamalıdır. Antioksidan etkileri de mevcuttur ancak bu etki terapötik dozlarda değil, bu dozun 10 kat fazlasında ortaya çıkmaktadır [14]. Ülkemizde pirasetam Nootropil ampul ${ }^{\circledR}$ ve tablet $^{\circledast}$ formlarında bulunmaktadır. Özellikle akut vertigo atağı sırasında Nootropil ampul; hafıza sorunları yaşayan yaşlı hastalardaki vertigonun idame tedavisinde ise Nootropil tablet $^{\circledR}$ formu 3x1 pozolojide kullanılabilmektedir [5].

3.3.Trimetazidine (Vastarel $^{\circledR}$, Vasofix ${ }^{\circledR}$, Triplus $^{\circledR}$, Sitorel ${ }^{\circledR}$, Picadil $^{\circledR}$ ): Etki mekanizması tam olarakaydınlatılamamışolsa da antioksidan özelliği ile serbest oksijen radikallerinin üretimini inhibe eder. Sitoprotektif bir ajan olup vazodilatasyon etkisi ile kanlanmayı arttırır. Özellikle iskemik ve toksik stresS ortamında kokleovestibüler sistemi nöronal hasardan korur. Etkisini gösteren klinik çalışmalar vardır. Vertigo ve tinnitus üzerinde plaseboya göre daha etkili bulunmuştur [15]. Trimetazidine ve betahistin periferik vertigolu hastalarda karşılaştırıldığında eşdeğer derecede etkili bulunmuş, Meniere hastalığında ise etkinliğinin biraz daha fazla olduğu gözlenmiştir [16]. Gebe ve çocuklarda kullanılmaz. Monoamin oksidaz (MAO) inhibitörleri ile kullanılmamalıdır. Ülkemizde $3 \times 1$ pozolojide kullanılan $20 \mathrm{mg}$ tablet formu ile $2 \times 1$ pozolojide kullanılan $35 \mathrm{mg}$ modifiye salımlı tablet formları bulunmaktadır [5].

3.4.Sinnerazin: Bir antihistaminik olan sinnerazin zayıf sedatif ve antikolinerjik etki yanında antiemetik etkisi vardır. Klasik antihistaminiklere ait uyku, sersemlik hali, dikkatsizlik, kilo artışı gibi yan etkileri vardır. Taşıt tutmasında özellikle tercih edilir ancak araba kullanmak gibi dikkat gerektiren işlerde çalışanlarda kullanılması sakıncalı olabilir. Günlük doz 50-225 mg'dır [5].

3.5.Fluarizin: Merkezi sinir sitemine etklili bir kalsiyum antagonistidir. Sinnerazine benzeyen ancak daha kuvvetli etki ve yan etkileri vardır. Uzun süreli kullanımında ekstrapiramidal etkileri de ortaya çıkabilir. Fonksiyonel vertigo hastalarında özellikle tercih edilir [17]. Günlük doz 5 mg'dır [5].

3.6.Gingo glikozidleri: Gingo biloba ağacının yapraklarının kuru ekstresinden elde edilen ekstre, hem antioksidan hem de platelet aktive adici faktör (PAF) antagonisti olarak etki gösterir. Bitki yapısında doğal olarak bulunan antioksidanlar serbest radikalleri bağlar. Ayrıca ilacın serebrovasküler düzenleyici etkisi, vertigo kontrolü ve iskemik nöron hasarını önleme gibi etkileri olduğunu gösteren çalışmalar vardır. Yapılan karşılaştırmalı çalışmalarda semptomlar üzerine betahistin kadar etkili oldğu saptanmıştır [18]. Daha çok vasküler yetmezlik, algısal bozukluk ve santral denge bozukluklarında etkili olabileceği düşünülmekle beraber, periferik vertigolu hastalarda rehabilitasyona eklendiğinde kompanzasyonu hızlandırdığı bildirilmiştir [19]. Vasküler vestibüler hastalıklarda betahistin vestibülooküler refleksi baskılarken Gingko bilobanın düzelttiği görülmüştür [18]. Hayvan çalışmalarında Ginkgo biloba ekstresinin tek taraflı vestibüler hasar sonrası kompanzasyonda etkili olduğu, spontan oküler nistagmus gibi belirtilerin düzelmesini hızlandırdığı bildirilmiştir [20].

Pozoloji 3x1 şeklinde ve günlük doz 120-240mg kadardır. Kanama diyatezi olan hastaların kullanması önerilmez [5].

3.7.Steroidler: Yapılan epidemiyolojik, histopatolojik ve hayvan çalışmalarda vetigonun sık nedenlerinden biri olan vestibüler nörinitin viral inflamasyon nedeniyle oluştuğuna dair güçlü kanıtlar mevcuttur [21-23]. Sadece vestibüler nörinitde değil, henüz tanısı konulmamış "akut vestibuler vertigo"da da steroidlerin etkinliği belirtilmiştir. Arıyasu ve ark.'nın yaptığı çalışmada metilprednizolon 16mg 2x1 pozolojide 3 gün kullanılan hastalarda vertigo ve nistagmus semptomlarında erken dönemde azalma saptanmıştır [24]. Steroidlerin bir etkisi de vertigoda tek taraflı vestibüler hasar sonrası ortaya çıkan stres yanıtlarını etkilemesi ve vestibüler kompanzasyonu hızlandırmasıdır [25].

\section{Pediatrik vertigoda tedavi}

Pediatrik vakalarda görülen vertigo, oldukça çeşitli etyolojik faktörlere dayanır. Hastalığın nadir görülmesi ve anamnez almadaki zorluklar nedeniyle tedavide standart protokoller bulunmamaktadır [26]. Pediatrik vertigonun altında yatan nedenin aydınlatılması ve buna yönelik tedavi uygulanması esastır. Vertigo çocukluk çağında en sık siklik kusma ve migren ile karışır [27]. Bu sebeple kusma şikayeti ile 
başvuran hastalarda altta vertigo hastalığının yatabileceği unutulmamalıdır. Pediatrik vertigo tedavisinde semptomatik tedaviden ayrı olaran diüretikler, özellikle pediatrik Meniere hastalığında ilk seçilecek ilaçtır [28]. Dihidroergotamin, izosorbit uygulanabilecek diğer tedavi seçenekleridir [29]. Tedaviye dirençli vertigo vakalarında, sistemik yan etkilerden kaçınmak için intratimpanik gentamisin tedavisini öneren yayınlar bulunmaktadır [30].

Sonuç olarak vertigo medikal tedavisinde kullanılan ilaçlar çeşitlilik göstermektedir. Hastanın öncelikle klinik ve tanı testleri ile olarak değerlendirilmesi, daha sonra gerek görüldüğü takdirde uygun medikal tedavinin başlanması gerekmektedir.

\section{Maddi Destek ve Çıkar İlişkisi}

Çalışmayı maddi olarak destekleyen kişi/kuruluş yoktur ve yazarların çıkara dayalı bir ilişkisi yoktur.

\section{Kaynaklar}

1. Ciuman RR. Inner ear symptoms and disease: Pathophysiological understanding and therapeutic options. Med Sci Monit 2013; 19 : 1195-210.

2. Huh YE, Kim JS. Bedside evaluation of dizzy patients. J Clin Neurol 2013; 9: 203-13.

3. Zanni GR, Wick JY. Vertigo: few new spins on a common problem. Consult Pharm 2006; 21: 680-96.

4. Sajjadi H, Paparella MM. Meniere's disease. Lancet 2008; 372: 406-14.

5. Vademecum 2013 modern ilaç rehberi, 35.baskı, Nobel kitabevi.

6. Zajonc TP, Roland PS. Vertigo and motion sickness. Part II: Pharmacologic treatment. Ear Nose Throat J 2006; 85: 25-35.

7. Renner UD, Oertel R, Kirch W. Pharmacokinetics and pharmacodynamics in clinical use of scopolamine. Ther Drug Monit 2005; 27: 655-65.

8. Lin E, Aligene K. Pharmacology of balance and dizziness. NeuroRehabilitation 2013; 32: 529-42.

9. Huppert D, Strupp M, Mückter $H$, Brandt T. Which medication do I need to manage dizzy patients? Acta Otolaryngol 2011; 131: 228-41.

10. Venail F, Biboulet R, Mondain M, Uziel A. A protective effect of 5-HT3 antagonist against vestibular deficit? Metoclopramide versus ondansetron at the early stage of vestibular neuritis: a pilot study. Eur Ann Otorhinolaryngol Head Neck Dis 2012; 129: 65-8.

11. Della Pepa C, Guidetti G, Eandi M. Betahistine in the treatment of vertiginous syndromes: a meta-analysis. Acta Otorhinolaryngol Ital 2006; 26: 208-15.

12. Nauta JJ. Meta-analysis of clinical studies with betahistine in Ménière's disease and vestibular vertigo. Eur Arch Otorhinolaryngol 201; 217: 887-97.

13. Mukhopadhyay S, Niyogi M, Ray R, Mukhopadhyay BS, Dutta $M$, Mukherjee M. Betahistine as an add-on: The magic bullet for postoperative nausea, vomiting and dizziness after middle ear surgery? J Anaesthesiol Clin Pharmacol 2013; 29: 205-10.
14. Oosterveld WJ. The effectiveness of piracetam in vertigo. Pharmacopsychiatry 1999; 32: 54-60.

15. James AL, Thorp MA. Menière's disease. Clin Evid (Online). 2007 Mar 1; 2007. pii: 0505.

16. Orhan I, Aydın S, Altın G, Yılmaz F. An efficacy comparison of betahistin, trimetazidine and ginkgo biloba extract in patients with tinnitus. Kulak Burun Bogaz Ihtis Derg 2013; 23: 143-7.

17. Lepcha A, Amalanathan S, Augustine AM, Tyagi AK, Balraj A. Flunarizine in the prophylaxis of migrainous vertigo: a randomized controlled trial. Eur Arch Otorhinolaryngol 2014; 271: 2931-6.

18. Cesarani A, Meloni F, Alpini D, Barozzi S, Verderio L, Boscani PF. Ginkgo biloba (EGb 761) in the treatment of equilibrium disorders. Adv Ther 1998; 15: 291-304.

19. Diamond BJ, Shiflett SC, Feiwel N, et al. Ginkgo biloba extract: mechanisms and clinical indications. Arch Phys Med Rehabil 2000; 81: 668-78.

20. Maclennan K, Smith PF, Darlington CL. Ginkgolide B accelerates vestibular compensation of spontaneous ocular nystagmus in guinea pig following unilateral labyrinthectomy. Exp Neurol 1995; 131:273-8.

21. Sekitani T, Imate $Y$, Noguchi T, Inokuma T. Vestibular neuronitis: epidemiological survey by questionnaire in Japan. Acta Otolaryngol Suppl 1993; 503: 9-12.

22. Silvoniemi P. Vestibular neuronitis. An otoneurological evaluation. Acta Otolaryngol Suppl 1988; 453: 1-72.

23. Hirata Y, Gyo K, Yanagihara N. Herpetic vestibular neuritis: an experimental study. Acta Otolaryngol Suppl 1995; 519: 93-6.

24. Ariyasu L, Byl FM, Sprague MS, Adour KK. The beneficial effect of methylprednisolone in acute vestibular vertigo. Arch Otolaryngol Head Neck Surg 1990; 116: 700-3.

25. Dutia MB. Mechanisms of vestibular compensation: recent advances. Curr Opin Otolaryngol Head Neck Surg 2010; 18: 420-4.

26. Akagi $H$, Yuen $K$, Maeda $Y$, et al. Ménière's disease in childhood. Int J Pediatr Otorhinolaryngol 2001; 61: 259-64.

27. Russell G, Abu-Arafeh I. Paroxysmal vertigo in children an epidemiological study, Int J Pediatr Otorhinolaryngol 1999; 1:105-7.

28. Filipo R, Barbara M, Juvenile Me'nie're's disease, J Laryngol Otol 1985; 99: 193-6.

29. Parving A, Me'nie're's disease in childhood, J Laryngol Otol 1976; 90: 817-21.

30. Nedzelski JM, Bryce GE, Pfleiderer AG. Treatment of Me'nie're's disease with topical gentamicin: A preliminary report, J Otolaryngol 1992; 21: 95-101. 